\title{
La función negativa de la literatura en Situations II de Jean-Paul Sartre
}

\author{
SANTIAGO BELLOCQ \\ Universidad Nacional de San Martín
}

Resumen: Para Jean-Paul Sartre, la literatura es una (o la) herramienta privilegiada para revelar el mundo y llamar a la libertad creadora de los hombres, ya que por su misma naturaleza significativa la totalidad del ser-en-el-mundo del para-sí se ve trastocada en sus fibras más íntimas en tanto se despliega esencialmente en la misma sustancia de la conciencia: la negatividad. La "literatura total" que el autor plantea en Situations II implica un doble movimiento de negatividad y construcción, réplica de la síntesis irresoluble que el para-sí es. El presente artículo desarrolla entonces esta función negativa/crítica de la literatura desde la filosofia sartreana, haciendo hincapié en la función social que emana de esta y cómo dicha negatividad se ha ido gestando históricamente hasta culminar en el surrealismo, movimiento criticado desde esta perspectiva por Sartre.

Palabras clave: negatividad, compromiso existencial, libertad, creación, surrealismo. 


\title{
Literature's Negative Function in Jean-Paul Sartre's Situations II
}

\begin{abstract}
Literature is for Jean-Paul Sartre one of most privileged tools for revealing the world and calling for men's creative freedom, for its significant nature changes all the being-in-the-world structure of the beingfor-itself as it unfolds on the same substance of consciousness: negativity. The notion of "total literature" that the author considers in Situations II implicates a double movement of negativity and construction, exactly like the insolvable synthesis that the being-for-itself is. This paper will develop then this negative/critic function of literature following Sartre's philosophy, emphasizing in the social function that is detached from it and showing its historical origins that culminate in the surrealist movement, which is strongly criticized by him.
\end{abstract}

Key-words: negativity, existential engagement, freedom, creation, Surrealism.

\section{La obra de arte literaria: llamamiento a la libertad, recreación del mundo y compromiso existencial}

A lo largo de Situations II (publicado en 1948), Jean-Paul Sartre Amuestra cómo el objeto literario, obra de arte principalmente significativa, es producto de la acción conjunta del autor y el lector, presentándose, así, como un llamamiento, un reclamo de libertades que presentifican lo significado creándolo. La obra de arte es valiosa, dice Sartre, precisamente por ser este llamamiento que "existe únicamente cuando se la mira y que es [...] exigencia pura de existir" (2008: 80); concordando con Kant, desde esta óptica la obra de arte no tiene finalidad, pero porque es un fin en sí misma al hacerse una con la libertad del que contempla o lee, en este caso. Y desde L'être et le néant (1943 Iv, 1:508-638) sabemos que existencia y libertad son lo mismo en la filosofia sartreana.

Ahora bien, ¿cómo este objeto logra ser estético si, desde una primera aproximación, pareciera ser solo un signo transparente y neutro del mundo que nos remite más allá de sí? Sartre no es en absoluto un esteta, lo cual no significa que en sus obras uno no encuentre una belleza inusitada; se encuentra más bien del lado de Martin Heidegger, para quien vale más la "verdad" que esa obra significa y manifiesta que lo "bella" que pueda ser ("la belleza es uno de los modos de la verdad", pero no viceversa). La belleza en la prosa no es más que "una fuerza dulce e imperceptible" que se expresa 
en la armonía de las palabras, en el equilibrio de las frases que disponen las pasiones del lector sin que este se dé cuenta; por eso Sartre afirma que, "en la prosa, el placer estético es puro únicamente cuando viene de añadidura" (Sartre 2008: 64). Pretender imponerle sensaciones al lector sería contradictorio con la esencia misma de estas obras, pues no operaría propiamente una espontaneidad creadora en ello: buscar afectarlo sería apuntar a su pasividad, no a su actividad libre. Por otra parte, la disposición realizada finamente por el escritor se perdería además si el autor buscara que el lector se detuviera en cada palabra por sí misma, como ocurre en la lectura de la poesía; ello conduciría a una opacidad que no permitiría el avance fluido por las líneas del texto, deteniendo constantemente la marcha y no alcanzando su fin:

el escritor no debe tratar de turbar [...]; si quiere exigir, debe limitarse a proponer la tarea que hay que realizar. Se deduce de esto el carácter de pura presentación que parece esencial a la obra de arte: el lector debe contar con cierta posibilidad de repliegue estético. (Sartre 2008: 81)

Este repliegue es el que manifiesta el mundo de una manera novedosa, debido a la modificación estética del proyecto humano. La "alegría estética"1 que acompaña a la conciencia posicional -para la cual el mundo es un valor, o sea, una tarea propuesta a la libertad humana- es consecuencia de que el mundo se identifique con el objeto estético en tanto que es imaginado (y por ello, irrealizado y recreado en una proyección libre). Mientras que normalmente el mundo se presenta como el horizonte de nuestra situación, como la totalidad sintética del enunciado, como el conjunto indiferenciado de obstáculos y útiles, en esta nueva modalidad se nos presenta como dirigiéndose a nuestra libertad. La alegría estética a la que se hace mención se debe no solo al reconocimiento de sí por sí de la libertad, sino fundamentalmente al cambio estructural operado en el nivel intraconsciencial donde se interioriza lo "no-yo" por excelencia (el en-sí), donde a partir de ahora el datum es percibido como imperativo y el hecho bruto como valor. Por esta modificación el mundo es percibido como mi tarea, en la que la función

\footnotetext{
1 "El escritor, como todos los otros artistas, quiere procurar a sus lectores cierta emoción a la que la costumbre denomina placer estético y que, por mi parte, llamaría más a gusto alegría estética [...]; esta alegría, en efecto que está negada al creador mientras crea, se identifica con la conciencia estética del espectador, es decir [...] del lector. [...] Se identifica por de pronto con el reconocimiento de un fin trascendental y absoluto que suspende por un momento la cascada utilitaria de los fines-medios y los medios-fines, es decir, de un llamamiento [...]" (Sartre 2008: 88).
} 
esencial de mi libertad es precisamente hacer del ser, en un movimiento incondicionado, el objeto único y absoluto del universo:

la conciencia posicional es conciencia imaginante del mundo en su totalidad, como ser y deber ser a la vez [...], [que] encierra realmente la totalidad armoniosa de las libertades humanas en la medida en que esa totalidad es objeto de una confianza y una exigencia universales. (Sartre 2008: 90)

La prosa como obra de arte esclarece el ser como ser, con toda su opacidad y coeficiente de adversidad, por medio de la espontaneidad indefinida de la existencia, es decir, de la libertad: todo el ser se haya penetrado hasta lo más hondo por esta libre trascendencia que lo revela con una luz nueva. Vemos entonces que la obra de arte nunca es un dato natural, sino exigencia y donación, pura gratuidad, pues la gratuidad es la imagen misma de la libertad. ${ }^{2}$ Los sentimientos de los lectores, al no estar nunca dominados por el objeto presentado y como no hay (normalmente) una realidad exterior que pueda condicionarlos, son "completamente generosos" ya que poseen su fuente permanente en la libertad, pues Sartre llama generoso precisamente a un sentimiento que tiene la libertad por origen y fin. Para nuestro filósofo, "el arte es aquí una ceremonia del don y el solo don origina una metamorfosis" (Sartre 2008: 84): la de la entera realidad humana y el mundo que ella crea.

De esta manera el libro, en tanto obra de arte, no sirve a la libertad, sino que la requiere; para alcanzarla efectivamente, debe primero reconocerla y luego confiar en ella: no hacerlo sería olvidar que la imaginación del lector no es solamente una función reguladora sino una instancia constitutiva de la obra. Cada palabra leída es un camino de trascendencia, donde escribir "es pedir al lector que haga pasar a la existencia objetiva la revelación que [el autor ha] emprendido por medio del lenguaje" (Sartre 2008: 78). El libro, dice Sartre, se propone como fin la libertad del lector: pero esa libertad significa revelación del mundo, manifestación que no lo deja intacto sino que lo convierte en una totalidad enteramente recreada por la praxis humana:

\footnotetext{
2 "En una sociedad que insiste en la producción y reduce el consumo a lo estrictamente necesario, la obra literaria es algo evidentemente gratuito. Aunque el escritor subraye el trabajo que la obra le cuesta [...], continúa siendo verdad que el objeto creado no es en modo alguno asimilable a un bien. Esta gratuidad, lejos de afligirnos, es nuestro orgullo; sabemos que es la imagen de la libertad. La obra de arte es gratuita porque es fin absoluto y se propone al espectador como un imperativo categórico" (Sartre 2008: 221-222).
} 
el acto creador persigue una reproducción total del mundo. Cada cuadro y cada libro es una recuperación de la totalidad del ser; cada obra de arte presenta esta totalidad a la libertad del espectador. Porque tal es el objetivo final del arte: recuperar este mundo mostrándolo tal cual es, pero como si tuviera su fuente en la libertad humana. (Sartre 2008: 87, las cursivas nos pertenecen)

Por las implicaciones recíprocas de la exigencia mutua de sus libertades, escritor y lector entregan de nuevo la totalidad del ser al hombre como tarea por realizar mediante la acción sobre el mundo (véase Wittman 2001: 35-52).

En esta instancia, Sartre afirma que lo propio de la conciencia estética es ser "creencia por compromiso", no solo entendido como acto de fe sino como compromiso real y ontológico donde me veo obligado a crear lo que él revela. Si el oficio del escritor consiste en representar al mundo y dar testimonio de él, el lector deberá comprometerse enteramente en la recreación libre de lo ahí abierto ya que, en este plano, la percepción es acción. En efecto, la mostración del mundo que los escritores ejercen en la literatura implica siempre "revelarlo en la perspectiva de un cambio posible" (Sartre 2008: 266), manifestando al lector en cada caso concreto su facultad de hacer y deshacer, de actuar, de acuerdo con las posibilidades que abre. Sartre expone que escribir, al revelar el mundo y proponerlo como una tarea a la generosidad del lector, es ubicarse en un plano de esencialidad respecto a la totalidad del ser; sin embargo, el mundo verdaderamente real solo se revela en la acción (véase Sartre 1996), y solo puede ser descubierto en la literatura mediante el movimiento que busca trascenderlo pasándolo para cambiarlo, es decir, negándolo. Para que el mundo presente su máximo de densidad "es necesario que la revelación-creación por la que el lector descubre este mundo sea también alistamiento imaginario de la acción; dicho de otro modo, cuanto más gusto se tenga en cambiarlo, tanto más vivo será" (Sartre 2008: 90). Sabemos que para Sartre el hacer es revelador del ser: por nuestro proyecto es que los entes intramundanos se presentan como siendo de tal o cual manera. De lo que se trata entonces ya no es de "poseer" el mundo, sino de cambiarlo, ya que "es al propio proyecto de cambiarlo a lo que el mundo revela los secretos de su ser" (Sartre 2008: 224). Así como en Heidegger (1927: SS 14-18) el conocimiento más íntimo de algo se obtiene en su uso y en la relación práctico-significativa que ello mantiene con la totalidad de los seres, es necesario también en la literatura hundir las cosas y empaparlas en la acción, aunque sea en un plano imaginario; ahí la densidad de ser será medida por el lector de acuerdo con la cantidad de relaciones prácticas que las cosas y personajes tengan entre sí.

No debemos olvidar que fue por los mismos años que Sartre escribió Situations II y su ensayo Vérité et existence, aparecido póstumamente; de ahí que ambos textos estén plagados de esta visión aletheizante de la acción y la 
libertad humanas. El hombre es el medio por el que las cosas se manifiestan: no hace que las cosas sean (nunca podría ser fundamento del en-sí) sino que permite que haya cosas diferenciadas, pues su carácter nihilizador es introductor de la diferencia en el ser-en-sí. El hombre es el ser frente al cual nada puede resultar neutro, frente al cual las cosas y los hombres mismos se descubren como verdad. Esta, recordamos, solo se da "en relación con este punto de vista que hace que un mundo exista y se devele en la sucesión" (Sartre 1996: 136), es decir, como verdad situada. Ahora bien, Sartre aclara que hay en toda verdad una relación interna con la propia libertad:

Mi libertad interioriza la finitud, pero, al mismo tiempo, deja un porvenir de libertad con respecto al presente finito [...], presenta un porvenir in-definido en el que será libertad consciente y determinante en relación con el presente concebido como libre desvelamiento del en-sí. [...] Al ser toda libertad desvelamiento, mi verdad presente será finitud nuevamente exteriorizada desde el punto de vista de otra veri-ficación todavía indeterminada [...]: toda verdad revelada es a la vez un absoluto y algo indeterminado. (Sartre 1996: 137)

Esta relación entre libertad y verdad no aparece explicitada en demasía en Situations II, y sin embargo resulta altamente gráfica para comprender el juego que ocurre en el seno de la literatura y la libertad. Efectivamente, el hecho de desvelar la verdad del mundo mediante la literatura revela al propio hombre no solo su libertad (porque la reclama) sino a su vez su propia finitud, fundamento último de toda su existencia libre (pues a su vez reclama una nihilización para iluminar un mundo en la pro-yección). Como podemos ver en el análisis fenomenológico realizado en L'être et le néant, es por la negatividad esencial de la existencia-libertad que algo así como revelación, acción o cambio son posibles, pues de lo contrario el en-sí sería intrascendible. El mundo presentado por el escritor debe ser negado en orden a trascenderse y rebasarse; así, la literatura no solo nos devuelve la conciencia y la experiencia fundantes de nuestra libertad ${ }^{3}, \operatorname{sino}_{\text {que nos fuerza a }}$ ejercer la nihilización de una manera privilegiada al iluminar una verdad que demanda necesariamente nuestra acción negativa, pues, justamente y como precisaremos luego, la literatura en sí misma es negatividad.

Hay que tener en cuenta, no obstante, que la particularidad del fenómeno que ocurre en la literatura como escritura-lectura que realza y po-

3 “[...] el escritor, hombre libre que se dirige a hombres libres, no tiene más que un tema: la libertad” (Sartre 2008: 93). Podríamos agregar, si profundizamos, que no tiene por tema más que la negatividad. 
tencia precisamente esta facultad humana donde la acción se da por revelación es que se da en un plano donde lo que prima es la negatividad que opera mediante el lenguaje. La palabra, aquí, es responsable total de la nihilización y trascendencia ek-stática de la situación en la que me veo inmerso y del mundo en su totalidad:

Hablar es actuar [...]; al hablar, descubro la situación por mi mismo propósito de cambiarla; la descubro a mí mismo y a los otros para cambiarla [...]; con cada palabra que digo, me meto un poco más en el mundo y, al mismo tiempo, salgo de él un poco más, pues lo paso en dirección al porvenir. (Sartre 2008: 61)

Lo que se ve aquí es propiamente el sentido del compromiso en su acepción ontológica, en cuanto que estoy con-pro-metido: metido como el "en" del ser-en-el-mundo, arrojado fácticamente en él a la vez que lo proyecto, con Otros que me rodean y que me reclaman y a los que exijo libertad. Es esta la idea fundamental del compromiso sartreano, siendo su aplicación "política" su prolongación natural, la otra cara de este mismo y único fenómeno. Sería contradictorio ser-en-el-mundo sin estar comprometido en él, ser-en-el-lenguaje si no estoy enteramente transido por la significatividad, ser libre sin estar comprometido en mi situación proyectada. Más allá de su sentido político, lo fundamental para Sartre será primero comprometerse a defender la libertad, antes que cualquier otra cosa; aunque luego, aclara, ese compromiso se jugará propiamente en el "proteger la libertad concreta y cotidiana, tomando partido en las luchas políticas y sociales" (Sartre 2008: 61).Y, para un escritor, esto implica saber que su palabra es acción, su revelación es cambio y que incluso la mera concepción de revelar sin proponer un cambio es imposible. El lenguaje será probablemente el lugar más idóneo para ejercer un trabajo negativo que permita modificar la situación estructural del mundo en que vivimos, ya que "pensamos con palabras", y nuestro pensamiento mismo es lenguaje; más aún, somos lenguaje en tanto ser-para-otro, en tanto totalidad significativa. Así es que la función del escritor consiste en obrar de modo que ya nadie pueda ser inocente o neutro frente a un mundo por ignorarlo; lanzado al universo del lenguaje, no puede simular que no sabe hablar puesto que "si se entra en el universo de los significados, ya no hay modo de salir de él" (Sartre 2008: 63). Cada frase literaria contiene de algún modo el lenguaje entero y remite en ello a todo el universo: $y$ de esta manera, el mundo que la literatura pone al desnudo se muestra como estando bajo nuestra total responsabilidad, como siendo nuestra tarea, aun si pretendemos rechazarlo. El autor nos compromete para asumir la responsabilidad del universo entero al mostrarnos la relación entre hacer y ser desde la perspectiva de nuestra situación histórica, al atraparnos como lectores mediante sus personajes y tramas: 
[lo que pide al lector] no es la aplicación de una libertad abstracta, sino la entrega de toda la persona, con sus pasiones, sus prevenciones, sus simpatías, su temperamento sexual, su escala de valores. Cuando esta persona se entrega con generosidad, la libertad le atraviesa de parte a parte y transforma hasta las masas más oscuras de su sensibilidad.Y, como la actividad se ha hecho pasiva para crear mejor el objeto, la pasividad, recíprocamente, se convierte en acto: el hombre que lee ha subido a lo más alto. (Sartre 2008: 82)

Según Sartre, el hombre que lee se transforma:

se despoja en cierto modo de su personalidad empírica y escapa de sus resentimientos, sus miedos y sus codicias para colocarse en lo más alto de su libertad; esta libertad toma la obra literaria como fin absoluto y hace otro tanto $[\ldots]$ con la humanidad: se constituye en exigencia incondicionada respecto de sí misma, al autor y a los lectores posibles. (Sartre 2008: 250)

Es así como la libertad es la clave hermenéutica fundamental para comprender la idea sartreana de la literatura, sin perder nunca de vista que lo que opera de fondo son siempre movimientos espontáneos de negatividad tanto en el proceso de la experiencia estética del leer como en la proyección de mundos posibles que se abren al campo de nuestro accionar revelador. Al comprometernos en lo más íntimo y reflejarnos nuestra esencia libre, la literatura se presenta como una praxis que ofrece un plus de nihilización a aquella que ya somos cotidianamente, pues ayuda de algún modo a negarnos reflexivamente gracias a la mediación del objeto imaginario-irreal (véase Sartre 1940), “destruyendo” nuestra situación fáctica (y nosotros con ella) para recrearla (y recrearnos) nuevamente en una iluminación de verdad que nos incrusta una vez más en la historia. ${ }^{4}$ Ahora bien, como ya dijimos, la literatura no es posible si no exige, además de mi libertad, la libertad de todos los hombres. Conocemos la posición de Sartre en la que, por más condicionada que esté su situación, el hombre es un centro de indeter-

\footnotetext{
${ }^{4}$ Algo prácticamente idéntico es lo que acontece en el teatro. Como dice Sartre, "si es cierto que el hombre es libre en una situación dada y que se elige a sí mismo en y por esta situación, entonces hay que mostrar en el teatro situaciones simples y humanas y libertades que se eligen en esas situaciones. [...] Lo más emocionante que puede mostrar el teatro es una personalidad en el proceso de hacerse, el momento de la elección, de la libre decisión que compromete una moral y toda una vida. La situación es un llamado; nos concierne: nos toca a nosotros decidir" (Sartre 1992: 20). Teniendo en cuenta su esencial origen "literario", todo lo expuesto hasta aquí compete también a este tipo de arte.
} 
minación irreductible. El hombre no es ciertamente más que su situación, pero esta considerada como un en-sí sería algo neutro e indiferente si una libertad humana no le confiere algún sentido mediante su pro-yecto original. Esta elección de nuestra situación implica nuestra íntima responsabilidad, nuestro compromiso total, no solo porque nos abarca a nosotros sino porque compete una elección de todos los hombres. Según Sartre es precisamente al "hombre total", totalmente comprometido y libre, a quien de hecho hay que liberar, aumentando sus posibilidades de elección; he ahí la función de la literatura:

Esa libertad no existe, si hablamos con propiedad; hay que conquistarla en una situación histórica; cada libro propone una liberación concreta a partir de una enajenación particular [...]: este mundo es la enajenación, la situación, la historia, y es este mundo lo que debo tomar y asumir, lo que debo conservar o cambiar, para mí y los demás. Porque, si el aspecto inmediato de la libertad es el negativo, se sabe que no se trata del poder abstracto de decir no, sino de una negatividad concreta que retiene en ella misma lo que niega y adquiere con ello, en todas sus partes, determinado matiz. (Sartre 2008: 97-98, las cursivas nos pertenecen)

Así es que vuelve a aparecer el para-otro como estructura constitutiva no solo de nuestra existencia sino del ser mismo de la literatura, pues ella es llamamiento a la libertad de todos los hombres. Debemos considerar entonces de qué manera la literatura ejerce su negatividad en el seno de la sociedad, entrelazando dialécticamente la singularidad del escritor/lector concreto con la situación histórica de su época para ganar así esta libertad.

\section{La función social de la literatura crítica}

( ) la libertad sea el fin de la literatura es reclamar esa libertad para todos los hombres; sería contradictorio pretender la libertad para unos pocos, pues esta reclama necesariamente cierta totalidad. Al mismo tiempo, el proceso que se da en el acto de lectura implica un proyectarse más allá de sí hacia un otro que no es solamente el autor sino también una comunidad más amplia: recordemos que para Sartre el hombre que lee "se despoja de su personalidad empírica" y se totaliza con la humanidad encarnada en los lectores posibles. Ese "concierto de voluntades", esa "ciudad de los fines" kantiana solo puede convertirse en una sociedad concreta cumpliendo dos condiciones: 
[...] la primera, que los lectores reemplacen el conocimiento de principio que tienen los unos de los otros en cuanto son todos ejemplares singulares de la humanidad por una intuición [...], un presentimiento de su presencia carnal en medio de este mundo; la segunda, que esas voluntades abstractas, en lugar de permanecer solitarias y de lanzar al vacío llamamientos que no llegan a nadie a propósito de la condición humana en general, establezcan entre ellos relaciones reales con ocasión de acontecimientos verdaderos, o, en otros términos, que [...] se historialicen conservando su pureza y transformen sus exigencias formales en reivindicaciones materiales y fechadas. (Sartre 2008: 250-251)

Como dijimos, es solo en situación que la literatura y la actividad del lector y el autor pueden tener un sentido verdadero, y por ello es necesario el arrojo a la historia, donde cada exigencia y cada acto tengan una fecha concreta, un sustrato material real, para no perderse en divagues idealistas o solipsistas que pierdan de vista la estructura social. Lo que se juega en la literatura no es solo la posibilidad de un placer estético, sino toda una metafísica y una construcción de la concepción metafísica de mundo y hombre, y por ello su pretensión es total.

El ejemplo que da Sartre sobre Richard Wright, que se dirigía a un público bien delimitado (negros cultos del norte de los Estados Unidos, y "norteamericanos blancos de buena voluntad"), es bastante conciso al señalar que finalmente se dirigía a todos los hombres, pero a través de esa focalización concreta. La "esencia" de la libertad se deja entrever en aquella liberación histórica y concreta, fechada, que Wright persigue (la libertad de los negros), mientras que al mismo tiempo "la universalidad del género humano está en el horizonte del grupo concreto e histórico de los lectores" (Sartre 2008: 104). Lo que hace ahí el escritor es mediatizar, ${ }^{5}$ nombrar y mostrar la vida cotidiana, ser la conciencia de todos, el movimiento por el que la raza se eleva de lo inmediato a la nueva consideración reflexiva de su condición. Se alza entonces una imagen de la humanidad que se pretende proyecto, humanidadpor-construir, ya que toda revelación, incluso de una idea metafisica, implica un cambio y un accionar sobre ella. Sartre pretende una literatura que toque y concilie lo absoluto metafísico y la relatividad del hecho histórico, que él llama "literatura de las grandes circunstancias". La reivindicación metafísica que hace es contundente, al enfrentarse a aquellos que la consideran como algo caduco, como discusiones estériles sobre nociones abstractas; para él

5 "El escritor es un mediador por excelencia y su compromiso es la mediación" (Sartre 2008: 102). 
consiste en "un esfuerzo vivo para abarcar por dentro la condición humana en su totalidad" (Sartre 2008: 212). Sin embargo, que la literatura sea de algún modo metafisica no significa que adopte el punto de vista de la eternidad, como pretendiendo escribir para una universalidad abstracta y eidética válida para todos los tiempos; ello no haría sino caer en vacuidades inútiles y ciegas, haciendo afirmaciones sobre "el Hombre" tan generales y amplias que abarcarían a todos sin tocar a nadie. ${ }^{6}$

Una literatura comprometida en su época se preocupará de problemas que, como dice Sartre, no tendrán sentido veinte años después: problemas que conciernen a una sociedad y un tiempo determinados; ello no quita que sin embargo la posteridad pueda encontrar ciertos contenidos de verdad "universales" (o, mejor dicho, verdades temporales que valgan también para su época y sus problemas concretos). Sartre dice que puede llegar a haber un reflorecimiento de una obra "epocal" desde este plano de universalidad, en el que "ya no será más eficiente, será considerada un objeto gratuito, [...] como si el escritor lo hubiera escrito gratuitamente y no por su valor preciso de acción sobre un hecho social preciso" (Beauvoir 1981: 244). Tal sería el caso por ejemplo de Voltaire, cuyas obras son actualmente leídas desde esta óptica como siendo válidas "universalmente", mientras que en su época solo extraerían su sentido de ciertos hechos sociales concretos. Según Sartre, los escritores conocen estos dos puntos de vista cuando escriben, y los tienen en cuenta -o quizás simplemente los pretenden. De esta manera, el arte de escribir es concebido como "fenómeno histórico y concreto, es decir, como el llamamiento singular y fechado que un hombre, aceptando historializarse, hace, a propósito del hombre entero, a todos los hombres de su época" (Sartre 2008: 138).

Se ve entonces cómo la literatura pasa a ser una cuestión del ámbito social, ya que su intención será a la fuerza contribuir a que se produzcan cambios en la sociedad, cambios en la condición social del hombre y en la concepción que el hombre tiene de sí mismo. Su ámbito de lucha es el de las ideologías, dentro del lenguaje; en efecto, debe buscar extraer la concepción del hombre en que se inspiran los hechos históricos concretos de la época, concepción que "anda por las calles" como perteneciendo al sentido común, y que debe ser precisada y aclarada para ayudar a su perpetuación o a su destrucción; es así que la literatura vuelve a recuperar su función social.

\footnotetext{
6 "No nos haremos eternos [...], no seremos absolutos por haber reflejado en nuestras obras algunos principios descarnados, lo suficientemente vacíos y nulos para pasar de un siglo a otro, sino por haber combatido apasionadamente en nuestra época, por haberla amado con pasión y haber aceptado morir en ella" (Sartre 2008: 13).
} 
El escritor proporciona a la sociedad una conciencia inquieta, y por ese motivo se encuentra constantemente en conflicto con las fuerzas conservadoras que mantienen el equilibrio que busca precisamente destruir; como más adelante dice basándose en Hegel, el paso a lo mediato solo puede hacerse por negación de lo inmediato, y esto significa ser una revolución perpetua. La manera en que podrá ejercer esta negatividad es desarrollando y realizando la literatura de manera que funcione como un espejo $\mathrm{crítico}^{7}$, donde la sociedad se vea y se encuentre en contradicción en lo más profundo de su situación, y donde esa contradicción le impulse a dar el salto negativo en la tarea de alcanzar su libertad. "Por medio de la literatura [...], la colectividad ${ }^{8}$ pasa a la reflexión y a la mediación y adquiere una conciencia turbada y una imagen desequilibrada de sí misma que trata sin tregua de modificar y mejorar" (Sartre 2008: 271). Esta tarea crítica se hace total, comprometiendo al hombre entero, y se compone de dos momentos; uno analítico o negativo y uno sintético o positivo/constructivo:

Si la negatividad es uno de los aspectos de la libertad, la construcción es el otro [...]; en la medida en que la literatura es negatividad, impugnará la enajenación del trabajo; en la medida en que es creación y avance, presentará al hombre como acción creadora y le acompañará en su esfuerzo para dejar atrás su enajenación presente en pos de una situación mejor. (Sartre 2008: 222)

Claramente esta mejora de la situación implica el advenimiento de la sociedad sin clases anunciada por Marx, autor que será el más influyente en este pensamiento sartreano de posguerra, ya que solo en ella puede realizarse el ideal tanto de libertad humana como de literatura. La literatura solo podrá identificarse con su esencia en esta instancia, ya que solo en esa sociedad podría el escritor advertir que no hay diferencia entre su tema y su público: la clave siempre ha sido el hombre-en-el-mundo -en su libertad-. En esa sociedad, la literatura sería:

7 “El hombre -escribe Sartre en Situations IX (publicado en 1972)-vive rodeado por sus imágenes. La literatura le da una imagen crítica de sí mismo [...]. Un espejo crítico. Mostrar, demostrar, representar. Eso es el compromiso. Después de eso, la gente se mira y hace lo que quiere [...]" (Sartre 1973: 24).

${ }^{8}$ Para Sartre, esta colectividad incluye la totalidad de la sociedad, burgueses y proletarios. La burguesía es tan víctima e inocente como tirana y culpable; lo que los escritores pueden y deben hacer es reflejar en su espejo su conciencia turbada, acelerar la descomposición de sus principios esencialmente analíticos, echarle en cara sus faltas. 
el mundo presentado a sí mismo, en suspensión en un acto libre y ofreciéndose al juicio de todos los hombres, la presencia reflexiva de una sociedad sin clases ante sí misma; sería por medio del libro como los miembros de esta sociedad podrían a cada instante precisar las cosas, verse y ver su situación. (Sartre 2008: 166)

Sartre procede a identificar literatura con subjetividad de una sociedad en revolución permanente, indicando que esa sería su verdadera esencia: una superación de la antinomia palabra-acción, donde la obra escrita sea la condición esencial para esta acción: el momento de la conciencia reflexiva donde la colectividad se juzga y, en ese juzgar (krínein), se metamorfosea. En su momento esencial, la literatura adquiriría, como el Espíritu hegeliano, plena conciencia de sí misma, y se haría total.

Tras lo aquí mostrado, puede volver a considerarse entonces la terrible y gigantesca responsabilidad que el escritor posee, según Sartre, ya que de él depende en gran medida que la sociedad pueda acudir al llamado hacia su propia libertad y autenticidad. El escritor ha de estar al tanto de su responsabilidad:

es responsable de todo: de las guerras perdidas o ganadas, de las revueltas y represiones; es cómplice de los opresores, si no es el aliado natural de los oprimidos. Pero solamente porque es escritor; porque es hombre. Tiene que vivir y querer esta responsabilidad, y para él, es lo mismo vivir y escribir [...] porque la vida se expresa en empresas y la empresa del escritor es escribir. (Sartre 2008: 43)

La escritura no es una actividad artística que derive en una "vida estética" bohemia e irresponsable, sino que es ante todo un oficio 9 que conlleva una gran responsabilidad, que incluso puede no haberse elegido ${ }^{10}$, y que requiere de unas técnicas y procedimientos particulares; lo que no implica ciertamente que se deje de lado el "estilo" o la búsqueda de perfección literaria: el arte, dice Sartre, nada pierde con el compromiso ya que siempre las nuevas exigencias de lo social o lo metafísico imponen al artista la necesidad de recrearse y desarrollar un lenguaje o técnicas nuevas. Muchos han objetado continuamente a su idea de compromiso literario el peligro al

9 “[...] escribir no es vivir, ni alejarse de la vida para contemplar en un mundo en reposo las esencias platónicas y el arquetipo de belleza [...]: es ejercer un oficio [...] [que] consiste en representar el mundo y dar testimonio de él” (Sartre 2008: 220 y 263).

10 “[...]la escritura y la política no se eligen. La situación decide” (Sartre 1973: 27). 
que sometería a la literatura al "comprometerla" tan crudamente, arguyendo que terminaría siendo una actividad panfletaria de corte comunista - probablemente alentados quizás por frases como "debemos militar en nuestros escritos en favor de la libertad de la persona y de la revolución socialista" (Sartre 2008: 255)-. Es posible que no hayan dado vuelta la página, donde el autor aclara muy bien que el principio rector es primero el de la libertad total, principio y fin de la literatura; y que, si bien se deben rechazar en todos los terrenos "las soluciones que no se inspiren rigurosamente en los principios socialistas", se debe apartar también "de todas las doctrinas que consideren al socialismo como el fin absoluto" (Sartre 2008: 256). Para Sartre, el socialismo no es el fin último sino "el último medio antes del fin", que es poner a la persona humana en posesión de su libertad. Solo en esta reivindicación la literatura puede ser salvada y guardada en su autenticidad, ya que ella misma es toma de posición frente a todas las injusticias, posición que busca desengañar al público. La enajenación de la literatura de una época se da precisamente cuando esta no llega a la conciencia explícita de su autonomía, cuando se somete a los poderes temporales o a ideologías (véase Sartre 2008: 161); las diversas formas de opresión y enajenación, así como ocultan a los hombres que son libres, también ocultan a los escritores la verdadera esencia crítica de la literatura.

Así es que, como todo hombre, el autor está comprometido en su situación, aunque de una manera más "lúcida" ya que sus escritos, "como todo proyecto humano, encierran, precisan y dejan atrás esa situación, la explican y la fundamentan incluso" (Sartre 2008: 160). Podríamos incluso arriesgar que el escritor comprometido se presenta como el modelo ideal de todo compromiso humano, recurriendo naturalmente a la analogía respectiva a cada situación concreta; consciente de su situación, revela el mundo para cambiarlo, disuelve mitos, ideologías y fetiches "en un pequeño baño de ácido crítico", procediendo a un llamado casi heroico de las libertades singulares a construir la sociedad sin clases. Solo recuperando y promoviendo su función social es que la literatura puede realmente alcanzarse a sí misma en su esencia. Sin embargo, debemos precisar mejor cómo se da efectivamente esta función crítica desde el doble movimiento de análisis-síntesis, destrucción-construcción, negatividad-positividad, que será el eje central de la dinámica esencial de la literatura y que nos permitirá entender mejor cómo la negatividad se ha ejercido y se ejerce social e históricamente a lo largo de los siglos. 


\section{Desarrollo histórico de la literatura como negatividad- construcción y crítica del surrealismo}

7 al como venimos desarrollando, el primer momento de la literatura que se quiere revolucionaria y liberadora es el momento del análisis, la instancia propia de destrucción y diferenciación por negación y que se fusiona de algún modo con la literatura y el pensamiento crítico-analíticos. Hay varias etapas en el desarrollo de la literatura como negatividad, que culminará en la aventura surrealista como su punto álgido donde se auto-aniquilará, y que tiene su origen en el espíritu analítico de la burguesía. Sin embargo, debemos trazar antes el parcours de este movimiento negativo hasta sus orígenes en la Edad Media, para comprender así cómo y por qué la modernidad ha desarrollado y usado (a veces hipócrita o inauténticamente) esta herramienta; como todo en el pensamiento sartreano, no podemos separar la "esencia" o el sentido de lo que la literatura ha ido deviniendo sin tener en cuenta sus particularidades históricas y sus devenires práxicos generados por la propia contradicción de hombres singulares.

En efecto, ha habido una constante tensión en la situación de todos los escritores desde que existe algo así como un "oficio" de la literatura, provocada por la relación con las clases dirigentes. Corrientemente el escritor era de algún modo un parásito de ciertos mecenas que lo apañaban y que fiscalizaban de algún modo su poder de destrucción, únicos que podían darse el lujo de retribuir una actividad tan importante como peligrosa. Ya que la literatura era el reflejo de la época, esta clase deseaba verse reflejada de modo casi narcisista sin tener en cuenta que luego iba a tener que asumirse críticamente -algo por lo general evadido mediante la mala fe-. El escritor está ahí funcionalmente frente a los intereses de quienes le hacen vivir, y debe existir y escribir con esa contradicción permanente sin resolverla jamás. Este conflicto sin embargo podía verse mitigado enormemente en el patético caso en que el público virtual era nulo y en que el escritor, en vez de estar al margen y frente a las clases privilegiadas, se veía absorbido por ellas. Es lo que ocurría precisamente en la Edad Media, donde la literatura se identificaba con la ideología de los dirigentes eclesiásticos por lo que la meditación y la reflexividad crítica que debía aparecer ahí se daba tan sutilmente que resultaba ser una simple perpetuación de la situación estamental. Hacia el siglo XII los clérigos escribían para los clérigos, y podían así permanecer con su conciencia tranquila dado el divorcio entre lo espiritual y lo temporal; incluso si se le debe al cristianismo el haber provocado el advenimiento de lo espiritual como negatividad y trascendencia perpetua, esta espiritualidad negativa se encontraba aún enajenada. El clérigo escritor ni siquiera tenía que preocuparse por el efecto que tendría en las masas ya que estas, anal- 
fabetas e incultas, jamás se enterarían de nada: hombre de Iglesia fundido en el inmenso cuerpo etéreo de Cristo, su deber era defender y mantener perpetuamente el dogma eterno.

Esta condición se mantuvo, según Sartre, hasta el siglo XVII, cuando en Francia, más allá de la laicización del escritor y el público, se debía si no conservar el dogma al menos no confrontarlo. Identificado aún con la ideología dominante, no se debía reinventar críticamente ni decidir sobre el valor mismo de su literatura ya que eso estaba asegurado aún por el peso de la tradición; en el momento en que una sociedad adopta una forma relativamente estable y se compenetra con el mito de su perennidad, confundiendo el presente y lo histórico con lo eterno y lo tradicional, es que ella y sus escritores se convierten en clásicos. En este clasicismo cada obra del espíritu debe ser un acto de cortesía hacia las clases, y el retrato del mundo y la sociedad que el escritor muestra es "abstracto y cómplice" al ignorar deliberadamente al hombre en su trabajo y su relación práctica con la naturaleza exterior. ${ }^{11}$

El quiebre hacia la negatividad comienza a darse en el momento en que la burguesía se presenta como clase potencialmente ascendente, es decir, como clase que sufre cierta forma de opresión (meramente política, pero opresión al fin) y que puede efectivamente constituirse en público real que puede leer, que intenta pensarse en esa lucha, y que necesita verdaderamente tomar conciencia de sí: ahí es donde por primera vez el escritor, sin salir de su tensión (pues aún es mantenido por la nobleza y. al mismo tiempo, los burgueses compran sus libros), puede desarrollar una literatura que refleje su época en el llamamiento a la libertad y la conciencia crítica de la sociedad. La burguesía tiene necesidad del escritor para verse "desde afuera", y así por primera vez la literatura reconoce su autonomía:

la literatura, que no era hasta entonces más que una función conservadora y purificadora de una sociedad integrada, adquiere conciencia en él y por él de su autonomía. [...] [A su vez] declara repentinamente su independencia: ya no reflejará los lugares comunes de la colectividad y se identifica con el Espíritu, es decir, con la facultad permanente de formar y criticar las ideas. (Sartre 2008: 124)

\footnotetext{
${ }^{11}$ Esto no significa que no pueda reconocerse nada valioso en la literatura clásica, como Sartre bien aclara: "Sin embargo, casi a pesar suyo, el espejo que presenta modestamente a sus lectores es mágico: cautiva y compromete. Aunque se haya hecho todo lo posible para ofrecerles una imagen halagadora y cómplice, más subjetiva que objetiva, más interior que exterior, esta imagen sigue siendo una obra de arte, es decir, algo que tiene su fundamento en la libertad del autor y que es un llamamiento a la libertad del lector" (Sartre 2008: 118).
} 
Aunque esta incipiente reconquista de la literatura por sí es todavía abstracta y casi meramente formal, ya comienza a confundirse con la negatividad como duda, crítica e impugnación. Espiritualidad, literatura y verdad están a partir de ahora ligadas en el momento abstracto y negativo de la toma de conciencia: ahí surge novedosamente el análisis como instrumento, "método negativo y crítico que disuelve perpetuamente los datos concretos en elementos abstractos y los productos de la historia en combinaciones de conceptos universales" (Sartre 2008: 125). El análisis será el arma que definirá desde ese momento al espíritu de la burguesía, y todo será analizado al desintegrar elementos compuestos en sus elementos simples. Al reducir el agua a hidrógeno y oxígeno se pudo encontrar su naturaleza "inmutable"; en el mismo movimiento, se desintegró el corpus social a la suma de individuos que lo componen, encontrando así la naturaleza inmutable del hombre como individuo. Así como este desvanecimiento de los conjuntos trajo aparejada una concepción donde las relaciones y combinaciones eran un momento más bien azaroso y posterior, derivado, se fundó en ello el principio eterno de los Derechos del Hombre, construyéndose la burguesía el mito de lo universal -libertad, igualdad, fraternidad- para su propio uso desde la individualidad. En materia política, la acción debía ser totalmente negativa: no se debía construir ninguna naturaleza humana, sino simplemente distinguir y separar los obstáculos que impedían su natural desarrollo. Esta negatividad analítica, inicialmente ofensiva al desmantelar el Antiguo Régimen, tomó tras las revoluciones una posición defensiva y conservadora en la que, luego de haber obtenido el poder político que deseaba, debía ahora perpetuar el orden universal de las cosas; es decir, al perpetuar la opresión de la gigantesca masa del proletariado, buscaba mantenerse en el poder. ${ }^{12}$

Si bien durante esta época la literatura recupera su actividad al llamar a los lectores a ejercer su libertad, el triunfo político de la burguesía vuelve a trastornar la condición del escritor y vuelve a poner en tela de juicio el estatus de la literatura: se le pide casi abandonar su negatividad para ayudarla a construir las nuevas bases futuramente eternas de su predominancia. El resentimiento y el rechazo que esto produce en los autores será la causa de

12 “[...] como el burgués no se siente muy seguro de sí mismo, como su poder no se basa en un decreto de la Providencia, será preciso que la literatura le ayude a sentirse burgués de derecho divino. De este modo, la literatura corre peligro, tras haber sido, en el siglo XVIII, la conciencia turbada de los privilegiados, de convertirse en el siglo XIX en la serena conciencia de la clase opresora [...]; mientras la burguesía luchaba contra el privilegio de la nobleza, se adaptaba a la negatividad destructora. Ahora, ya en el poder, pasa a la construcción y pide que se le ayude a construir" (Sartre 2008: 131). 
que una gran parte de ellos -los que hoy son consideradores los grandes escritores del siglo XIX- rechace abiertamente tanto su condición burguesa como a sus mismos lectores. Hacia 1848, indica Sartre, no hay ya modo de disimular la contradicción profunda que pone en choque la ideología burguesa con las pretensiones de la literatura. No queriendo traicionar su carácter negativo, el escritor se aparta de la sociedad burguesa a la que detesta y de la cual proviene, lo cual eventualmente dará lugar a posiciones herméticas como l'art pour l'art y el parnasianismo que concurrirán finalmente en el advenimiento de la Negatividad como lo absoluto, hasta su misma hipostasiación. En tanto artistas, sus obras son también un llamamiento sincero a la libertad de los lectores que, según Sartre, simulan despreciar. Sin entrar en detalles, diremos solamente que la obra literaria postromántica, llevando la impugnación al extremo, concluye en la impugnación de sí misma, al mismo tiempo que "nos invita a salir al vacío por medio de la destrucción de todos los mitos y cuadros de valores; nos descubre en el hombre, en lugar de la relación íntima con la trascendencia divina, una relación estrecha y secreta con la Nada" (Sartre 2008: 157). Es decir que, de alguna manera, muestra al hombre quizás mejor que en ningún otro momento su esencia más íntima, su ser-nihilización(como)para-sí; sin embargo, al destruirse a sí misma, cae con ella la posibilidad del llamamiento, lo que resta probabilidades a la futura conquista de la libertad de los hombres. Tal es lo que sucede, para Sartre, con el surrealismo, revolución trunca por su negatividad exacerbada que termina por no liberar a nadie.

La relación de Sartre con Breton y su grupo ha sido muy ambigua desde sus primeros años; fundamentalmente, porque él mismo es de algún modo "heredero", a pesar suyo, de ciertos temas y modos propios del surrealismo; ${ }^{13}$ a su vez, porque han compartido una preocupación constante por la libertad y la política, aunque desde ópticas bien diferenciadas: "Sartre apunta primero a una libertad metafisica, finalmente moral; la libertad surrealista, incluso si no descuida jamás el campo político, está enteramente orientada hacia el arte" (Sicard 2011: 76). Esto llevará a una divergencia no solo debido a la noción de compromiso sartreana, sino respecto a la inutilidad de un

\footnotetext{
13 "Sartre es un heredero del surrealismo. Heredero a pesar suyo. En el primer Sartre literario, se ha remarcado una gran cantidad de veces la presencia de temas o elementos surrealistas en sus novelas o en sus cuentos: la naturaleza misma del héroe Roquentin y sus peregrinaciones en la ciudad que hace que no podamos dejar de pensar en Nadja, las desaventuras en los cafés, las insignias, la presencia de objetos, estatuas y artes primeros $[\ldots]$ sin tener en cuenta el consumo de mescalina en 1935 que desencadenó un imaginario animal; posteriormente la fascinación por la escritura y el dibujo automáticos en Wols [...]” (Sicard 2011: 74-75).
} 
gesto únicamente negativo que no contribuye a ninguna apuesta concreta y firme ni por el socialismo ni por el lugar de la escritura en sí misma, y menos por la libertad de los lectores. Aun cuando el surrealismo se hubo pretendido una liberación total del hombre, por su punto de vista "totalitario" (de herencia hegeliana), su movimiento se quedó estancado en el concepto sin llegar a su concreción real, ya que por su origen analítico no alcanzó a pensar al hombre como una estructura sintética, sino como un campo heterónomo de fuerzas contrapuestas y separadas (como lo consciente y lo inconsciente).

A su vez, vemos que en el surrealismo la literatura como negación absoluta deviene antiliteratura bajo el reinado de la burguesía. Si en ese tiempo se escribía para consumir el mundo dilapidando las tradiciones literarias y utilizando las palabras de una manera que estallaran en sus significados quedando solo la estela sonora de su irrealidad, con el surrealismo se llega a plantear incluso no solo el asesinato de la realidad sino el asesinato [sur]real de la sociedad y sus esquemas, como bien expresa la famosa frase de Breton: "el acto surrealista más sencillo consiste en bajar a la calle, revólver en mano, y tirar al azar, tanto como se pueda, contra la multitud". ${ }^{14} \mathrm{La}$ búsqueda es finalmente aniquilar el ser en su totalidad, supuestamente para llegar al momento de crear una nueva realidad basada en las potencias inconscientes de la imaginación pura y libre. Al declararse destrucción pura, la literatura escapa a todo juicio, se ubica mucho más allá del bien y del mal, ya que solo puede rendir cuentas algo que se plantea como tesis positiva. Con la provocación simbólica al asesinato, el escritor surrealista plantea su total irresponsabilidad, refugiándose "en el maquis de la escritura automática"; su destrucción sistemática, critica Sartre, nunca va más allá del escándalo por lo que puede después reclamar el derecho de escapar a sus consecuencias. $\mathrm{Su}$ afiliación al Partido Comunista es totalmente contingente, ya que "la negación, que es la esencia del surrealismo, no es más que una etapa para el P. C." (Sartre 2008: 187)..$^{15}$

${ }^{14}$ Esta destructividad radical del surrealismo amerita, según sostiene Sartre en Situations I (publicado en 1947), ser "objeto de un análisis existencial” (Sartre 1960: 161) que es lo que hará luego en sus estudios sobre Jean Genet (1952) y Stéphane Mallarmé (1986). Ya en “Aller et retour" de 1944, incluido en aquel primer volumen de Situations, establece la relación entre el gesto destructivo pero trunco de Brice Parain y el del surrealismo.

${ }^{15}$ Sobre esta relación con los comunistas, Sartre precisa: "La fuente profunda del error estriba en que el surrealismo no tiene el menor interés en la dictadura del proletariado y ve en la Revolución, como pura violencia, el fin absoluto, mientras que el comunismo se propone como fin la conquista del poder [...]. La oposición se manifestará cuando la Rusia soviética y [...] el Partido Comunista francés pasen a la fase de organización constructiva: el surrealismo, que sigue siendo negativo por esencia, se apartará de eso. Breton se acercará entonces 
Sartre asocia esta afiliación a la "juventud rebelde" de estos artistas, cuyo odio y rechazo a su familia y su sociedad recién salidos de la guerra se traducía en esta negación radical, rebelde y metafísica pero abstracta. El problema de fondo que plantea, y que extenderá luego al gesto poético de los postrománticos, es que la destrucción es un momento necesario pero parcial, un medio para lograr luego un fin positivo y general; lo que el surrealismo hace es detenerse en este medio negativo y hacer de él un absoluto, sin superarlo. Así es que "no ven la contradicción profunda que enfrenta estas destrucciones brutales y parciales con el proceso poético de anonadación que han emprendido", y la abolición con la que sueñan no lastima a nadie por ser abstracta, así como es abstracta e indirecta (o inexistente) su relación con el proletariado. El trabajador destruye para construir, y conoce así las dos caras de la libertad, que es negatividad constructora; el surrealismo, al provenir del método analítico burgués, invierte el proceso y construye para destruir. El objeto creado, la obra real han sido construidas para autodestruirse simbólicamente:

muestra el orden humano invertido y, como tal, contiene en sí mismo su propia contradicción. Es lo que permite a su constructor pretender a la vez que destruye lo real y que crea poéticamente una superrealidad. En realidad, lo surreal así construido se convierte en un objeto más del mundo, un objeto en el que solo existe la indicación petrificada de la destrucción posible del mundo. (Sartre 2008: 283)

Así, el surrealismo queda descalificado y, si es valioso, lo es porque efectivamente destruye e inquieta las consciencias burguesas que son las que finalmente "consumen" ese arte, eliminando en ellos los últimos resabios de mitología cristiana que pudieran todavía tener.

Ahora bien, hay un factor considerable a remarcar, que es la acción y el efecto de la negatividad sobre el lenguaje. En esta literatura del siglo XIX, que desemboca en el surrealismo, se da una recuperación, como ya vimos, de esta función negativa que había sido abandonada, y que opera en primer lugar sobre el lenguaje al ser el material y el útil de los escritores, que debe ser "limpiado". El análisis propio del movimiento negativo es analogable a una deconstrucción en la que se ha de separar "en cada noción lo que propiamente corresponde y lo que le han añadido la tradición o los engaños de la opresión" (Sartre 2008: 257). El escritor opera

a los trotskistas, precisamente porque estos, acosados y minoritarios, se hallan todavía en la fase de la negación crítica" (Sartre 2008: 188-189). 
sobre estas capas de significaciones donde se fueron apilando sentidos que modificaban enteramente al lenguaje y por ende el ser-en-el-mundo del para-sí. Estas nociones, que son constitutivas de la objetividad del mundo y de la subjetividad de la sociedad, es decir, que influyen en nuestra situación, son el blanco de la destrucción surrealista y poética; si de lo que se trataba es de hacer que el mundo estalle y se aniquile (lo cual es imposible, ya que una destrucción real de la totalidad de los entes derivaría en un mero cambio de estado de esa totalidad-real), esto se lograría no solo mediante la creación de objetos imaginarios "surreales" sino por la destrucción del lenguaje mediante el empotramiento de las palabras; destrucción que, en el fondo, termina siendo creación, realización de la Nada por un exceso de Ser. El surrealismo conlleva según Sartre un "realismo" poético, en el que el lenguaje manifiesta su verdadera esencia mediante el empleo verdadero de la palabra, considerada como algo mágico en sí misma. Sartre indica que, para Breton, la utilización práctica de la palabra es una degradación del universo verbal ya que esta debe en verdad usarse de manera "surrealista"; herederos de Arthur Rimbaud y Lautréamont, hacen de la poesía el instrumento de sus revelaciones, donde "detrás del incendio de las palabras se entrevé el Ser: son terroristas" (Sartre 1952: 568). Es el mismo movimiento que iniciaron los parnasianos y, en su manera más radical, Stéphane Mallarmé: solo que, en verdad, lo que se podía ver más allá de esta destrucción era la Nada misma como origen y destino del lenguaje y del hombre. Este terrorismo de la palabra implica "un asco tan intenso por los signos como tales que induce a preferir siempre la cosa significada a la palabra, la palabra considerada como objeto a la palabra-significación, es decir, en el fondo, la poesía a la prosa" (Sartre 2008: 162-163). En el extremo, para sintetizar, Sartre ve lo siguiente:

[...] hay la esperanza de una creación absoluta [...] inutilizable en este mundo, porque no es de este mundo y no recuerda a nada: la imaginación [surrealista] es concebida como facultad de negar lo real y la obra de arte se edifica sobre el derrumbamiento del universo. Hay [...] el desarreglo sistemático de todos los sentidos y, para acabar, la destrucción concertada del lenguaje.Y hay también el silencio: ese silencio de hielo, la obra de Mallarmé [...], para quien toda comunicación es impura. [...] Se trata de negar el mundo o de consumirlo. De negarlo consumiéndolo. (Sartre 2008: 145)

Para Sartre, de lo que se trata hoy (al menos en 1947, pero que también podría ser válido setenta años después) no es ya "provocar incendios en los matorrales del lenguaje, de casar 'palabras que se queman' y de llegar a lo absoluto mediante la combustión del diccionario, sino de comunicarse 
con los demás hombres utilizando modestamente los medios con que se cuenta" (Sartre 2008: 28). El surrealismo, como toda literatura de la negatividad radical, se queda finalmente sin lectores y no alcanza a nadie, pues los ha rechazado expresamente prefiriendo la soledad y la torre de marfil tan propia del postromanticismo parnasiano. Frente a la negatividad pura, que es pura abstracción, Sartre propone una literatura concreta, que es "síntesis de la Negatividad, como poder de arrancarse a lo dado, y del Proyecto, como esbozo de un orden futuro" (Sartre 2008:167). Frente al puro espíritu analítico burgués, nuestro filósofo recurrirá a una concepción sintética de la realidad donde la totalidad es diferente en naturaleza a la suma de las partes, pero que al mismo tiempo no pierde este momento de análisis pues Sartre mismo y los escritores "comprometidos" que virtualmente lo acompañan son también ellos burgueses; solo les queda reflejar especularmente su conciencia turbada y acelerar la descomposición de sus principios.

Al descubrir en el arte de escribir la libertad en su doble aspecto de negatividad y avance creador, un obrero-lector puede verse críticamente y así tratar de liberarse al mismo tiempo que busca liberar a todos los hombres de la opresión: "oprimido, la literatura, como negatividad, podría reflejarle el objeto de sus cóleras; productor y revolucionario, es el tema por excelencia de una literatura de la praxis" (Sartre 2008: 235). Es en la síntesis de la destrucción y la construcción donde la literatura se hace realmente liberadora, donde su esencia se encarna más auténticamente. Además de la limpieza analítica de las palabras para "desembarazarlas de los sentidos adventicios", recalca Sartre, el trabajo que ha de efectuarse con el lenguaje debe ser sintético, agrandando y profundizando las significaciones, "cavando en los versos" para abrir puertas y adaptar las palabras a la situación histórica concreta que nos toca y que somos. Solo mediante el trabajo que conduzca a una colectividad socialista podrá la literatura, "tras haber comprendido finalmente su esencia y efectuado la síntesis de la praxis y la exis, de la negatividad y la construcción, del hacer, del tener y del ser, merecer el nombre de literatura total" (Sartre 2008: 226). Es lo que Sartre resume perfectamente al afirmar:

Si la literatura no es todo, no vale la pena perder en ella ni una hora. Eso es lo que entiendo por "compromiso". La literatura se muere si se la reduce a la inocencia, a canciones. Si cada frase escrita no resuena en todos los niveles del hombre y de la sociedad, no significa nada. La literatura de una época es la época digerida por su literatura. (Sartre 1973: 13) 


\section{BIBLIOGRAFÍA}

Beauvoir, S. de (1981), La cérémonie des adieux (suivi de Entretiens avec Jean-Paul Sartre), (París: Gallimard).

Heidegger, M. (1927), Sein und Zeit, (Tubingia: Max Niemeyer, 1957).

Sartre, J.-P. (1940), L'imaginaire, ed. de A. Elkaïm-Sartre (Buenos Aires: Losada, 1986)

Sartre, J.-P. (1943), L'être et le néant (París: Gallimard).

Sartre, J.-P. (1952), Saint Genet: comédien et martyr (París: Gallimard).

Sartre, J.-P. (1960), El hombre y las cosas (Situaciones I), trad. de L. Echávarri (Buenos Aires: Losada).

Sartre, J.-P. (1973), El escritor y su lenguaje y otros textos (Situations IX), trad. de E. Gudiño Kieffer (Buenos Aires: Losada).

Sartre, J.-P. (1986), Mallarmé: la lucidité et sa face d'ombre, ed. de A. Elkaïm-Sartre (París: Gallimard).

Sartre, J.-P. (1992), Un théâtre de situations (París: Gallimard).

Sartre, J.-P. (1996), Verdad y existencia, trad. de C. Amorós (Barcelona: Paidós)

Sartre, J.-P. (2008), ¿Qué es la literatura? (Situations II), trad. de A. Bernárdez (Buenos Aires: Losada)

Sicard, M. (2011), "Là où le réel fulgure: matiérisme et immaterialité dans l'esthétique sartrienne”, en P. Cabestan y J.-P. Zarader (comps.), Lectures de Sartre (París: Ellipses).

Wittmann, H. (2001), L'esthétique de Sartre: artistes et intellectuels, trad. de N. Weitemeier y J.Yacar (París: L'Harmattan).

Recibido: 13-02-2019; aceptado: 05-09-2019 